\title{
An Organizational Strategy and the Application of Spatial Data Based on the Dynamic Grid System
}

\author{
Huimin $\mathrm{Xu}^{1,2}$, Jun Yang ${ }^{2}$, Dewen Ding ${ }^{1}$ \\ ${ }^{1}$ School of Environment Science and Engineering \\ ${ }^{2}$ School of Urban and Environmental Sciences \\ Dalian Maritime University \\ Dalian,116026, P.R.China \\ Liaoning Normal University \\ dlxuhuimin@163.com \\ Dalian,116029, P.R.China
}

\begin{abstract}
Data grid is the fundamental work of graphics drafting, scientific computing and the realization of spatial analysis. The paper uses dynamic grid system and assigning technology of spatial data to implement interoperability of multiple-sources data. Assign grid system has multi-attributes, which applies geographic information system (GIS) and the external program to implement overlay analysis and other complicated spatial analysis functions. The merits of dynamic grid system are a complete vector format, the data quantity being small, implementing multiple sources data merging and spatial analysis of massive data.
\end{abstract}

Keywords-Dynamic Grid System; Spatial Overlay Analysis; Assigning Technology; Interoperability

\section{INTRODUCTION}

The core of geographic information system (GIS) is spatial analysis function, in which spatial overlay analysis is one of most important parts. For example, we use spatial overlay analysis to deal with reduction of cultivated land to forest, ecological evaluation and soil corrosion in a region.

There are two types of spatial analysis: one is based on raster data, the other is based on vector data. Most scholars in China and other countries implement spatial overlay analysis on the basis of raster data (Lu et al, 1998; Baja et al, 2001, 2002; Adriano et al, 2007; David et al, 1998; Zuo et al, 2003; Kevin, 1998; Anys et al, 1994; Larson et al, 2004; Li et al, 2000). For the spatial overlay analysis which we are using is based on raster data, if the region which is studied is very large, and the scale of the graphics is large, the massive raster data that is using in overlay analysis will call for high qualities of the hardware computer, and it will not do the spatial analysis under the complex mathematical model. Dynamic grid system is a kind of complete vector data format, implementing the merge of the data that come from multiple sources by interoperability methods such as assigning technology, and supporting the spatial analysis under the complex mathematical model (Andrew et al, 2006; Banerjee et al, 2005; Liu et al, 1998; Benson et al, 2006; Peppler et al, 2004; Manel et al, 2001; Yang et al, 2001; Michael et al, 2006; Alberti et al, 2005).

\section{DATA RESOURCES \& PROCESSING METHODS}

\section{A. Data Resources}

Data resources: 1:10000 topographic map of Lvshunkou in Dalian (1998), AutoCAD format; SPOT5 data of Lvshunkou in Dalian (2003), including a 2.5-meter panchromatic band and three 10-meter multi-spectral bands; 1:10000 land use data (2000), MapInfo format.

\section{B. Topographic Map Data Conversion}

1:10000 topographic map is in DWG format of AutoCAD without attributes. Converting DWG format into MapInfo format by using the tool of "Universal Translator" of MapInfo .Steps are as Fig.1 follows:

\begin{tabular}{|l|l|}
\hline Input & AutoCad Layer \\
\hline $\begin{array}{l}\text { Analysis: } \\
\text { Auto } \text { CAD into } \\
\text { MapInfo }\end{array}$ & $\begin{array}{l}\text { Create coordinate system for production } \\
\text { data by defined coordinate system }\end{array}$ \\
\hline Cutput & Convert layers into MapInfo data by \\
\hline AutoCAD data
\end{tabular}

Figure 1. Converting AutoCAD format data into MapInfo format data

\section{Programming for Contour Assigning}

There is no attribute of the contour and elevation points in 1:10000 topographic map, and the region of research is about 505.6 square kilometers. The contour interval of the mountain region is 5 meters, and the plain region is 2.5 meters. A program of the contour with assigning value is designed to reducing the heavy workload of the single assigning method. The workload of the single assigning method is very heavy, therefore, there is a designing program of the contour with assigning value to reduce the workload. The basic principle of contour assigning is: opening the contour file, drawing a line with mouse in the map window, judging how many times of intersection between the line with contour in the map window, in the meantime of the coming out of a dialog box, inputting elevation value of the first dialog box and increment in the step dialog box, the elevation values are assigned to the selected lines. The basic principle contour assigning is as Fig.2 follows: 


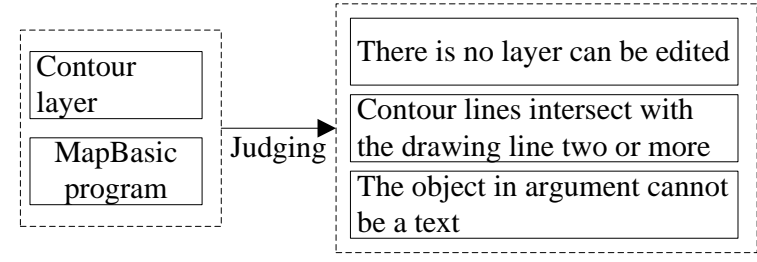

Figure 2. The basic principle contour assigning

\section{The Flow of the Contour Assign}

Because the conversion layer of the contour contains the annotations, the elevation points and the lines. The annotations, the points and the lines should be extracted firstly. And because the lines and the elevation points don't have elevation attributes, it is necessary to design a batch assigning program to assign value of the lines. The lines with elevation attributes are translated into the points with elevation attributes and then they merge into a new layer with the elevation points. Then through the terrain analysis function of GIS, creating DEM, slope, aspect etc. The flow of the contour assigning is as shown in Fig.3:

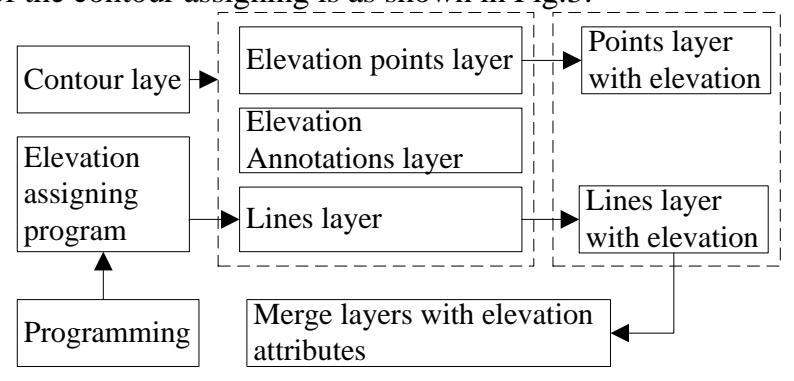

Figure 3. The flow of contour assigning

According to the flow, the colors of assigned contour lines are from brown to red, as shown in Fig.4:

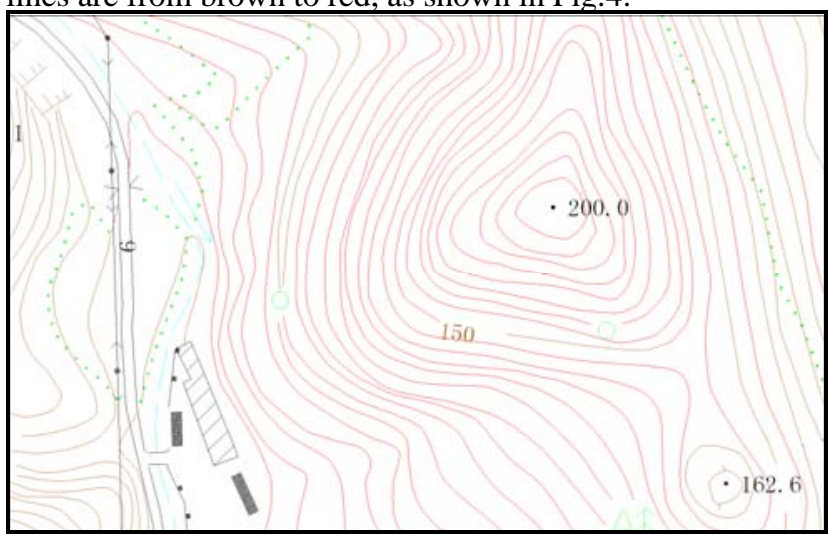

Figure 4. Map of contour assigning

\section{E. Land use data updating}

Updating land use data adopts the Spot5 remote sensing data in 2003 and the MapInfo format land use data in 2000. Spot 5 data have two types: 2.5-meter panchromatic band and 10-meter multi-spectral bands, applying DEM and digital topographic map to ortho-rectification original data. Merging ortho-processed data, the spatial resolution is $2.5 \mathrm{~m}$. The enhancement process of merge-image highlight the land use of topic information.

The applied MapInfo software carries on interactive process; updated land use data could be interacted after this process. Basic processes are as shown as Fig.5:

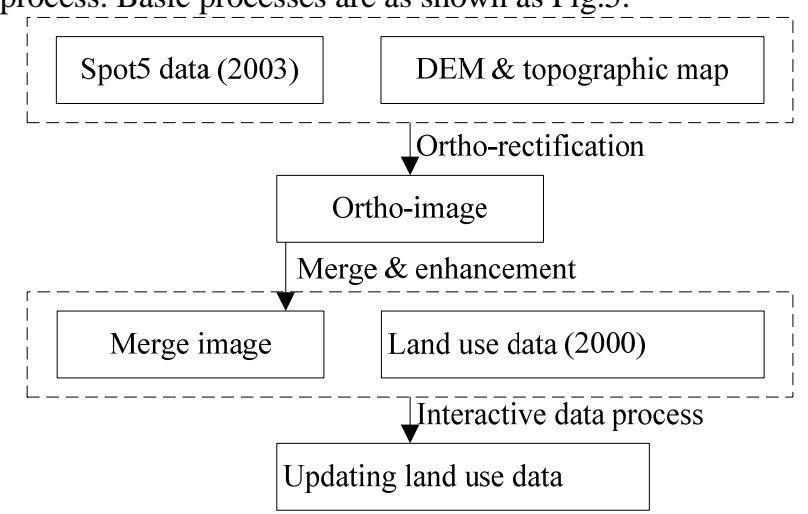

Figure 5. The flow of updating land use data

\section{DYNAMIC GRID SYSTEM}

\section{A. Gird Marker Programming}

Because the range of the study area is in difference, then the scale and the coordinate projection of the study graphics are different. In general, for small region with large scale, it adopts plane coordinate system and Gauss projection; for large region with small scale, it generally adopts longitudelatitude system. According to the realistic needs, adopts plane coordinate system or longitude-latitude coordinate system are adopted. This thesis selects plane coordinate system. The tool of GridMaker in MapInfo only supports the longitude-latitude coordinate system to create grids, but does not support the plane coordinate system to do so. Thereby, it needs the program designing to create grids. The basic principle of plane coordinate system is as shown in Fig.6:

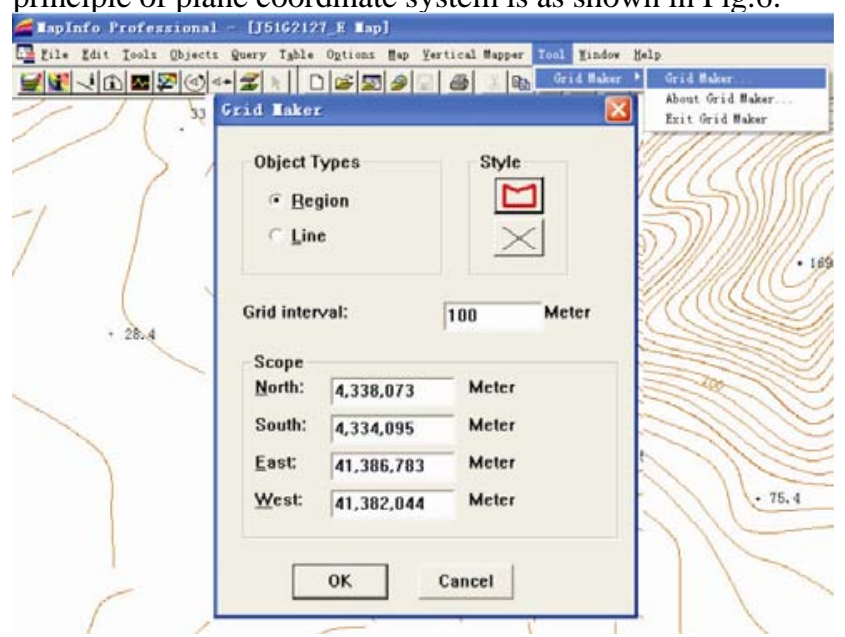

Figure 6. The grid maker program of plane coordinate system 


\section{B. Identity of Dynamic Grid System}

Dynamic grid system is a kind of square graph that is formed through programming, and is a kind of complete vector format. The size of the square depends on the size and the scale of the research area that is studied. Grid can design many fields according to the need of the users, and the fields can accept the attributes value of the data that come from many sources. As shown in Fig.7, users design many fields in accordance with their need to receive attributes of multiple sources data. To design the fields of attributes, we should be in accordance with their requirements and an open system. Therefore, the grid is a kind of dynamic grid.

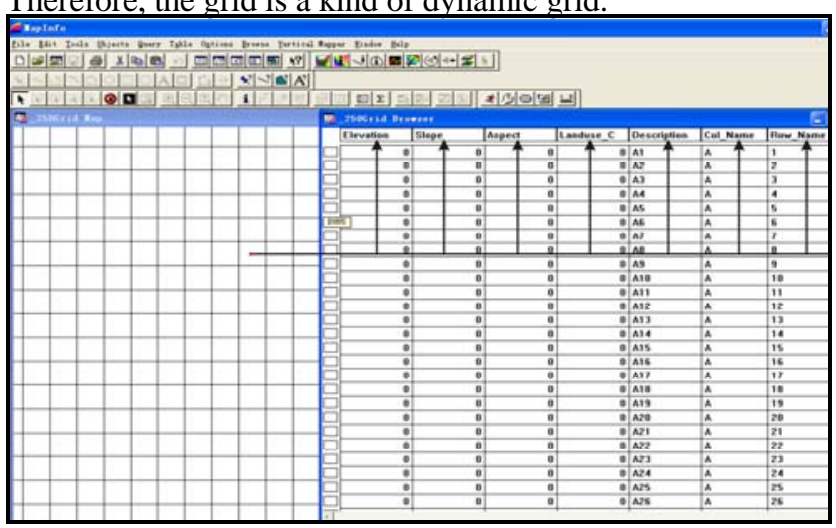

Figure 7. The structure of the dynamic grid

\section{DyNAMIC GRID System OF Multiple SOURCES DATA OBTAINING}

Multi-sources data obtaining is the fundamental of spatial analysis in dynamic grid system. Being supported by GIS, under the help of external program, multi-sources data assign attributes to dynamic grid system. With multi-attributes, grid can deal with complicated spatial analysis.

\section{A. Cell Assigning Programming}

We will assign attributes value to grid with either raster or vector data. The principle of cell assigning procedure is: Grid overlays multi-sources data, and the area of the grid should be bigger than the area of the multi-sources data; the fields structure of grid should be consistent with the fields structure of multi-source data; therefore, obtain the attributes value of the multi-source data automatically. The basic principle cell assigning as is shown in Fig.8:

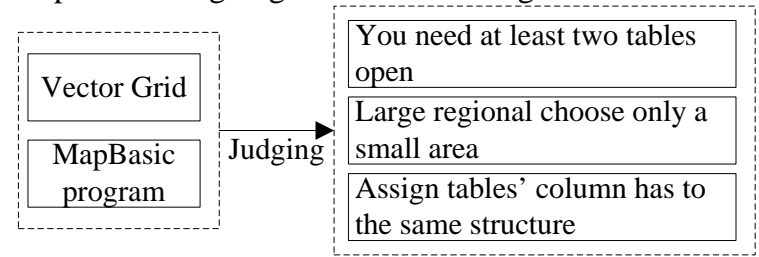

Figure 8. The basic principle cell assigning

\section{B. The Flow of Cell Assignings}

Multi-sources data obtaining is the fundamental of spatial analysis in dynamic grid system. Being supported by GIS, under the help of external program, multi-sources data assign attributes to dynamic grid system. With multi-attributes, grid can deal with complicated spatial analysis.

We will assign attributes value to grid with either raster or vector data. The principle of cell assigning procedure is: Vector grid overlays multi-sources data, and the area of the vector grid should be bigger than the area of the multisources data; the fields structure of gird should be consistent with the fields structure of multi-sources data; therefore, we can obtain the attributes value of the multi-sources data automatically. Fig. 9 shows the flow of cell assigning:

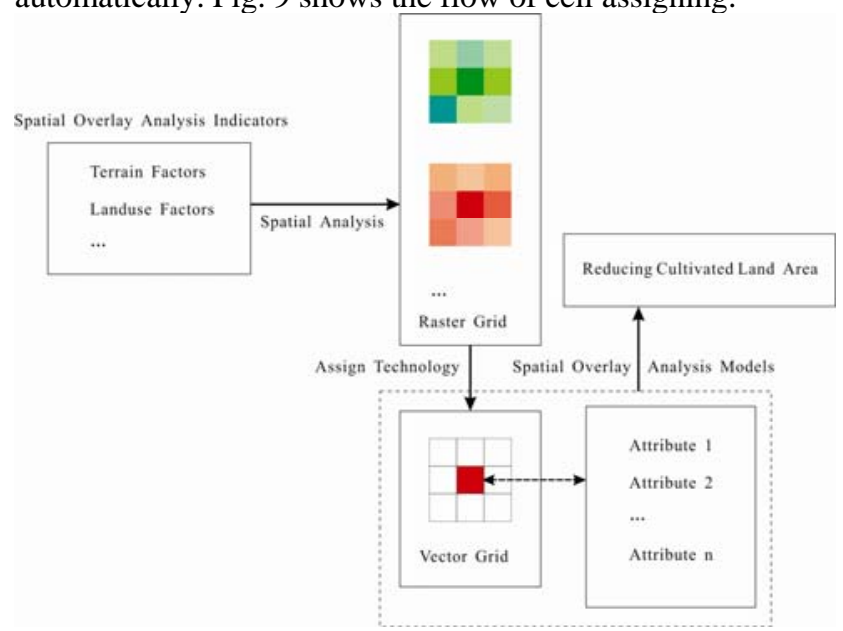

Figure 9. The flow of cell assigning

\section{Cell Assigning}

We use the terrain analysis function of GIS to obtain terrain factors, such as aspect, slope and so on. Terrain factor layers are converted to vector layer through the interoperability of spatial data. Land use data update via the remote sensing image and the old land use data with the methods of interactive processing. The steps of cell assigning are as shown in Fig.10:

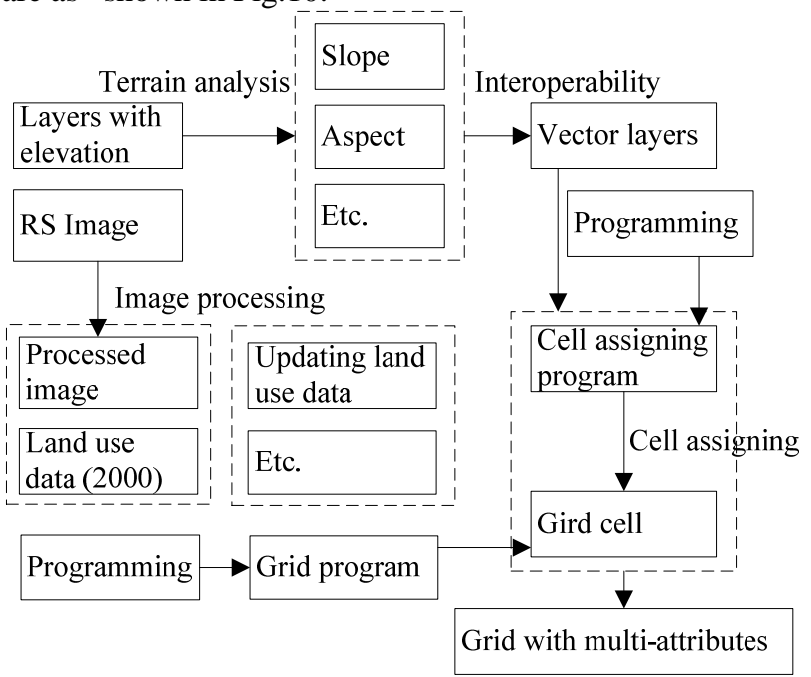

Figure 10. The steps of cell assigning 
Grid cell has multiple attributes after multi-sources data evaluation designing program. Land use data assigning graph is as shown in Fig.11:

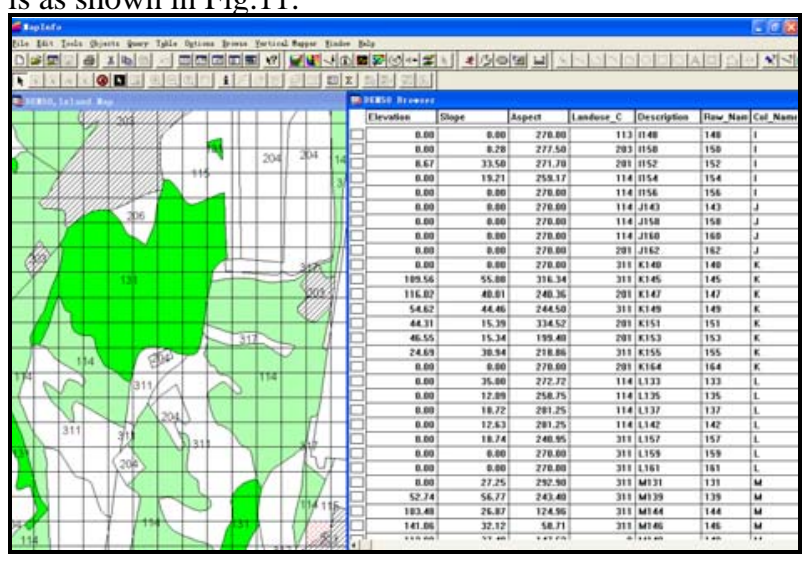

Figure 11. The map of cell assigning

\section{SPATIAL OVERLAY ANALYSIS RESULT}

We could calculate the reducing cultivated land to the forest region whose elevation is higher than 60 meters and whose slope is higher than 25 degrees by spatial overlay analysis. The red region is the contour lines of 60 meters and slope higher than 25 degrees region in the figure, the yellow region is the reducing cultivated land to forest region. The bottom map is 1:10000 topographic map, 1:10000 land use map and the ortho-image. The result of spatial overlay analysis is as shown in Fig.12:

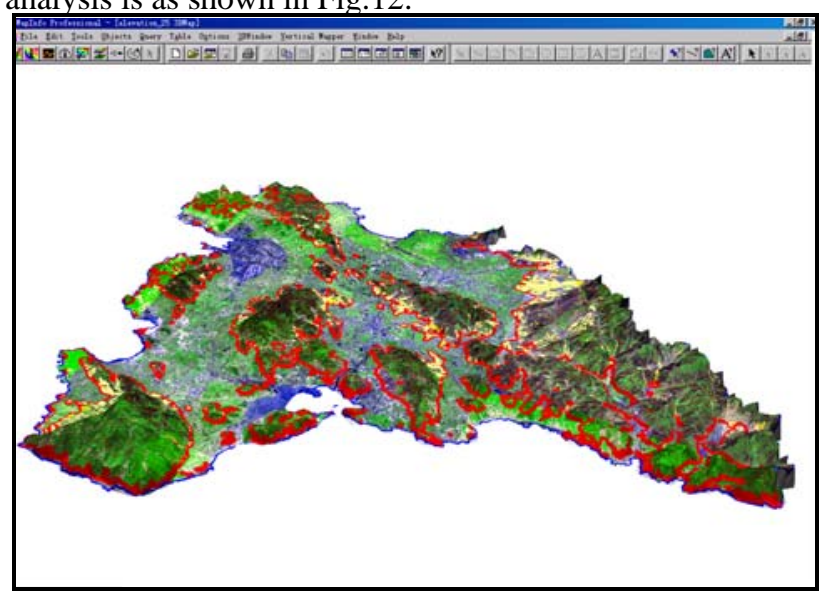

Figure 12. The result of spatial overlay analysis

\section{CONCLUSIONS}

This thesis puts forward a method of spatial overlay analysis on the basis of dynamic grid system, land use data, remote sensing data (RS data) and terrain data under the support of MapInfo, which implement the reducing cultivated land to forest region. Both spatial data organization of dynamic grid system and assigning technology implement spatial overlay analysis for massive data. Spatial data organization of dynamic gird system could change the size of gird according to the research region and scale. Therefore, the research precision could reach our demand. Dynamic grid system is a kind of complete vector data format which implements the merge of the data that come from multi-sources data by interoperability methods such as assigning technologies and supporting the spatial analysis under the complicated mathematical model.

\section{ACKNOWLEDGMENT}

The work described in this paper was substantially supported by the National Support Program of China (no. 2012BAC04B00).

\section{REFERENCES}

[1] Lu G., Qian Y.D., Chen Zh.M., “Automated Extraction of the Characteristic of Topography from Grid Digital Elevation Data. ACTA GEOGRAPHICA SINICA, 1998, 53 (6):562-569 (In Chinese).

[2] Baja, S., Chapman, D.M., Dragovich, D., "Fuzzy modelling of environmental suitability index for rural land use systems: An assessment using a GIS," In Proceedings of the Sixth International Conference on GeoComputation. 24-26 September, The University of Queensland, Brisbane, 2001.

[3] Adriano R.P., Walter C., "River reach length and slope estimates for large-scale hydrological models based on a relatively high-resolution digital elevation model,” Journal of Hydrology, 2007, 343:127-139.

[4] Baja, S., Chapman, D.M., Dragovich, D., “A conceptual model for defining and assessing land management units using a fuzzy modelling approach in GIS environment," Environmental Management, 2002, 29:647-661.

[5] David N. R., Douglas D., "GIS modelling of slope stability in Phewa Tal watershed, Nepal,” Geomorphology, 1998, 26:151-170.

[6] Zuo, W., Zhang G.L., Wan B.W., Li S., Wang Q., "Study of Determining the GIS Raster Size in Mid-scale Ecological Assessment Research,” Acta Geodaetica Et Cartographic Sinica, 2003, 23(3): 26771(In Chinese).

[7] Kevin h.J., "A Comparison of algorithms used to compute hill slope as a property of the DEM," Computers \& Geosciences, 1998, 24 (4): 315-323.

[8] Anys, H., Bonn, F., Merzouk, A., "Remote sensing and GIS based mapping and modeling of water erosion and sediment yield in a semiarid watershed of Morocco," Geocarto International, 1994, 9(1):3140.

[9] Larson, B.D., Sengupta, R.R., “A spatial decision support system to identify species-specific critical habitats based on size and accessibility using US GAP data," Environmental Modelling \& Software, 2004, 19:7-18.

[10] Baja, S., "The quality of the land: Using GIS for continuous-based land suitability assessment in the Sydney Region,” GIS User, 2001, 44: 32-35.

[11] Li, H., Gartner, D.I., Mou, P., Trettin, C.C., “A landscape model (LEEMATH) to evaluate effects of management impacts on timber and wildlife habitat," Computers and Electronics in Agriculture, 2000, 27:263-292.

[12] Andrew D.C., Richard G.T., Eric M.W., Marius L., “Applying spatial analysis to forest policy evaluation: case study of the Illinois Forestry Development Act," ENVIRONMENTAL SCIENCE \& POLICY, 2006, 9(3): 253-260.

[13] Sudipto B., Gregga A.J., Nick S., and Beverly R.D., "Modelling replicated weed growth data using spatially-varying growth curves," ENVIRONMENTAL AND ECOLOGICAL STATISTICS, 2005, 12 (4): 357-377.

[14] Liu, J., Ashton, P.S., "Formosaic: an individual-based spatially explicit model for simulating forest dynamics in landscape mosaics," Ecological Modelling, 1998, 106(2):177-200. 
[15] Benson V.S., VanLeeuwen J.A., Sanchez J., Dohoo I.R., Somers G.H., "Spatial analysis of land use impact on ground water nitrate concentrations," JOURNAL OF ENVIRONMENTAL QUALITY, 2006, 35(2): 421-432.

[16] Peppler-Lisbach, C., Schro"der, B., "Predicting the species composition of mat-grass communities (Nardetalia) by logistic regression modelling,” Journal of Vegetation Science, 2004, 15:623634.

[17] Manel, S., Williams, H.C., Ormerod, S.J., "Evaluating presenceeabsence models in ecology: the need to account for prevalence,” Journal of Applied Ecology, 2001, 38:921-931.

[18] Yang C.J., Liu J.Y., Zhang Z.X., Dang C.L., "Decisionon Reforesting and Regrassing Some of the Dry Sloping Cultivated with Support of GIS and Remote Sensing in Yunnan,” Journal of Geographical Sciences, 2001, 56(2):101-108 (In Chinese).

[19] Michael P. S. , A-Xing Z., James E. B., Cynthia S., "The effects of DEM resolution and neighborhood size on digital soil survey," Geoderma , 2006, 137:58-69.

[20] Alberti M., “Application of GIS to spatial analysis of mesofault populations,” COMPUTERS \& GEOSCIENCES, 2005, 31 (10):1249-1259.

[21] Li F., Wu Z.F., Xu C., Xu Y.D., Zhang L.B., “The spatial distribution of Ophiocordycepssinensis suitability inSanjiangyuan Region,” Acta Ecologica Sinica, 2014, 34(5):1318-1325(In Chinese).

[22] Fengchang X, Zhengfu B., "Spatial Overlay Analysis Based on Pan Boolean Function," Geomatics and Information Science of Wuhan University, 2009, 34(4):488-491(In Chinese).

[23] Hua F Z., "Study on the Method of DEM Assignment for the WideRange Sea Area Based on ERDAS," Geomatics \& Spatial Information Technology, 2011, 34(4):125-126(In Chinese).

[24] Jia L., Yankuo L., Lujun M., Guangyong X., Fangkai Y., "Habitat assessment of sika deer (Cervus nippon) in the Taohongling National Nature Reserve, Jiangxi Province,” China. Acta Ecologica Sinica, 2014, 34(5):1274-1283 (In Chinese).

[25] Liming C, Sicong G, Lingling B., "Fuzzy overlay analysis model based on Flou sets,” Application Research Of Computers, 2013, 30(1):130-133 (In Chinese).

[26] Lin D, Hong S, Xiao N., "Spatial Association Rule Mining Based on Overlay Analysis and Area Calculation," Geomatics and Information Science of Wuhan University, 2013, 38(1):95-99 (In Chinese).
[27] Ning C, Xiaoyu Z, Jianping L, Xiaoyu Z., Jianping L., Xueyi Z., Yinjuan H., et al., "Automatically assigning elevation value on topographic map in ArcView,” Agriculture Network Information, 2007, 9:61-62,71 (In Chinese).

[28] Tianhang X, Haisong A, Chao T., “A New Dynamic Mesh Generation Method for Large Movements of Flapping-wings with Complex Geometries,” ACTA AERONAUTICA ET ASTRONAUTICA SINICA, 2008, 29(1):41-47 (In Chinese)

[29] Wen Y., Dafang Z., Wu Y., Zhifeng T., Dongshen Q., "Distance Function for the Triangular Grids,” Acta Geodaetica et Cartographica Sinica, 2011, 40(1):59-65 (In Chinese).

[30] Wu D Z, Shi D G, Jun M H., "Dynamic Grid-based Method Research in Data Distributed Management," System Engineering Theory and Practice, 2007, 27(1):137-142 (In Chinese).

[31] Xiaogang G., Xianxiang H., Qiyuan Z., Zhili Z., "Research on Algorithm of Generating 3D Terrain from Contour Map Based on Auxiliary Line," Journal of System Simulation, 2011, 23(6):11911194.

[32] Xin Z, Yinbao Z., "Spherical Discrete Grid System Thinking Geospatial Data Integration,” Geomatics \& Spatial Information Technology, 2013, 36(9):26-29 (In Chinese).

[33] Xiyu S., Xiaolei Z., Yong H., Ge C., “Design and Implementation of Mobile Geography Information System Based on Oriented Multiple Data Integration,” GEOSPATIAL INFORMATION, 2012, 10(3):4851(In Chinese).

[34] Yahui P., Fangli X., "An Algorithm of Building DEM Based Dynamic Grid Template," JOURNAL OF ZHEJIANG INTERNATIONAL STUDIES UNIVERSITY, 2013, 4:87-92(In Chinese).

[35] Yong Y., Yuan R Z., "Land suitability evaluation based on multifactors analysis decision-making," Science of Surveying and Mapping, 2013, 38(4):37-39(In Chinese).

[36] Zhen Z, Heyu R., "Anitial Centroid Selected Algrithm Based on Dynamic Grid Technology,” Microelectronics \& Computer, 2013, 30(6):101-104 (In Chinese).

[37] Zhong K Z, Wei W W, Zhen L., "An Integrative Method of 3D Point Clouds Feature Segmentation and Fitting Fusing Multiple Data Source," Geomatics and Information Science of Wuhan University, 2013, 38(11):1317-1321 (In Chinese). 